\title{
Structural Changes of the Trinuclear Copper Center in Bilirubin Oxidase upon Reduction
}

\author{
Takaki Tokiwa ${ }^{1,2, *}$, Mitsuo Shoji ${ }^{3, *(\mathbb{D})}$, Vladimir Sladek ${ }^{4}$, Naoki Shibata ${ }^{5}$, Yoshiki Higuchi ${ }^{5}$, \\ Kunishige Kataoka ${ }^{6}$, Takeshi Sakurai ${ }^{6}$, Yasuteru Shigeta ${ }^{3}$ and Fuminori Misaizu ${ }^{1} \mathbb{D}$ \\ 1 Department of Chemistry, Graduate School of Science, Tohoku University, 6-3 Aoba, Aramaki, Aoba-ku, \\ Sendai, Miyagi 980-8578, Japan; misaizu@m.tohoku.ac.jp \\ 2 Department of Physics, Graduate School of Pure and Applied Sciences, University of Tsukuba, \\ 1-1-1’Tennodai, Tsukuba, Ibaraki 305-8571, Japan \\ 3 Center for Computational Sciences, University of Tsukuba, 1-1-1 Tennodai, Tsukuba, Ibaraki 305-8577, Japan; \\ shigeta@ccs.tsukuba.ac.jp \\ 4 Institute of Chemistry, Centre for Glycomics, Slovak Academy of Sciences, Dubravska cesta 9, \\ 84538 Bratislava, Slovakia; chemvls1@savba.sk \\ 5 Graduate School of Life Science, University of Hyogo, 3-2-1 Koto, Kamigori-cho, Ako-gun, \\ Hyogo 678-1297, Japan; shibach@sci.u-hyogo.ac.jp (N.S.); hig@sci.u-hyogo.ac.jp (Y.H.) \\ 6 Graduate School of Natural Science \& Technology, Kanazawa University, Kakuma, Kanazawa, \\ Ishikawa 920-1192, Japan; kataoka@se.kanazawa-u.ac.jp (K.K.); tasakura@staff.kanazawa-u.ac.jp (T.S.) \\ * Correspondences: t.tokiwa@dc.tohoku.ac.jp (T.T); mshoji@ccs.tsukuba.ac.jp (M.S.)
}

Academic Editors: Yasutaka Kitagawa, Ryohei Kishi and Masayoshi Nakano

Received: 20 November 2018; Accepted: 20 December 2018; Published: 26 December 2018

\begin{abstract}
Geometric and electronic structure changes in the copper $(\mathrm{Cu})$ centers in bilirubin oxidase (BOD) upon a four-electron reduction were investigated by quantum mechanics/molecular mechanics (QM/MM) calculations. For the QM region, the unrestricted density functional theory (UDFT) method was adopted for the open-shell system. We found new candidates of the native intermediate (NI, intermediate II) and the resting oxidized (RO) states, i.e., $\mathrm{NI}^{\mathrm{H}+}$ and $\mathrm{RO}_{0}$. Elongations of the $\mathrm{Cu}-\mathrm{Cu}$ atomic distances for the trinuclear $\mathrm{Cu}$ center (TNC) and very small structural changes around the type I $\mathrm{Cu}(\mathrm{T} 1 \mathrm{Cu})$ were calculated as the results of a four-electron reduction. The QM/MM optimized structures are in good agreement with recent high-resolution $\mathrm{X}$-ray structures. As the structural change in the TNC upon reduction was revealed to be the change in the size of the triangle spanned by the three $\mathrm{Cu}$ atoms of TNC, we introduced a new index $(l)$ to characterize the specific structural change. Not only the wild-type, but also the M467Q, which mutates the amino acid residue coordinating $\mathrm{T} 1 \mathrm{Cu}$, were precisely analyzed in terms of their molecular orbital levels, and the optimized redox potential of $\mathrm{T} 1 \mathrm{Cu}$ was theoretically reconfirmed.
\end{abstract}

Keywords: catalytic intermediate; protonation; $\mathrm{Cu}$ oxidation state; $\mathrm{X}$-ray reduction; $\mathrm{SONO}$; molecular orbital analysis

\section{Introduction}

Bilirubin oxidase (BOD) catalyzes the bilirubin oxidation using the reduction of dioxygen into water: 2 bilirubin $+\mathrm{O}_{2} \rightarrow 2$ biliverdin $+2 \mathrm{H}_{2} \mathrm{O}$. BOD belongs to the family of multicopper oxidases (MCOs) which contain unique $\mathrm{Cu}$ atoms, i.e., type I copper (T1Cu), type II copper (T2Cu) and type III copper $(\mathrm{T} 3 \mathrm{Cu})$. These $\mathrm{Cu}$ atoms have been classified based on their spectroscopic and magnetic properties [1]. BOD is a monomeric protein with a molecular mass of $60 \mathrm{kDa}$ and consists of three domains [2,3]. The $\mathrm{O}_{2}$ reduction is carried out at the trinuclear $\mathrm{Cu}$ center (TNC), which is composed of one $\mathrm{T} 2 \mathrm{Cu}$ and a pair of $\mathrm{T} 3 \mathrm{Cu}$ atoms, $\mathrm{T} 3 \mathrm{aCu}$ and $\mathrm{T} 3 \mathrm{bCu}$. T1Cu plays an essential role in electron 
transfer from the substrate to TNC. The pair of T3Cu ions in TNC of BOD is connected to T1Cu via His458-Cys457 and Cys457-His459 amino acids arranged in a Y shape, and the Cu centers are about 13 $\AA$ apart. In the same MCO family, there are ascorbate oxidase, ceruloplasmin, laccase, as well as BOD. The BODs have been widely utilized for the diagnostic analysis of bilirubin in serum. Recently, BODs have attracted attention for use as an enzymatic catalyst for the cathode of biofuel cells because of the high activity at neutral $\mathrm{pH}[4,5]$.

During the catalytic cycle of BOD, some intermediate states are formed [6,7] (Figure 1). In the fully oxidized state, two forms of the TNC have been characterized: the native intermediate (NI, intermediate II [8]) and the resting oxidized (RO) states. In the NI state, both the $\mu^{3}$-oxo and $\mu^{2}$-OH bridges connect the $\mathrm{T} 3 \mathrm{Cu}$ atoms, while in the $\mathrm{RO}$ state, only the $\mu^{2}-\mathrm{OH}$ bridge remains between the $\mathrm{T} 3 \mathrm{Cu}$ ions. As the transition rate from NI to RO is slower than the turnover rate of the catalytic cycle, NI is the actual catalytic center relevant to the oxidized form [9]. After a four-electron reduction, the fully reduced state (FR) is formed which contains all the $\mathrm{Cu}(\mathrm{I}) \mathrm{s}$, and the $\mathrm{OH}$ ligand coordinated to $\mathrm{T} 2 \mathrm{Cu}$ in the oxidized form is protonated to form $\mathrm{H}_{2} \mathrm{O} . \mathrm{O}_{2}$ can then bind to the unsaturated coordination sites in $\mathrm{TNC}$, and a two-electron reduced intermediate state, called the peroxy intermediate (PI, intermediate I [8]), is formed. After an additional two-electron reduction, the NI state is then regenerated.

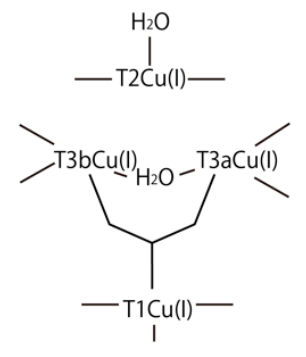

$\mathbf{F R}_{\mathbf{w}}$

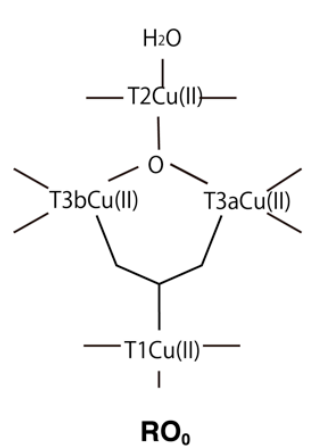

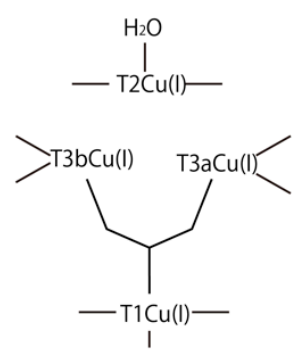

FR

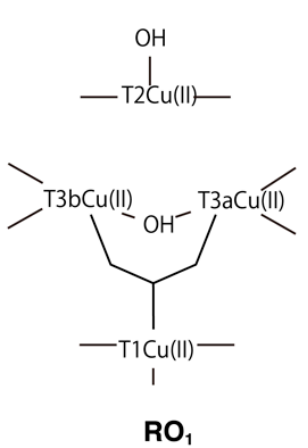

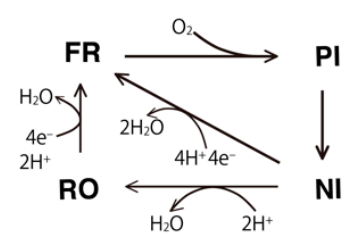

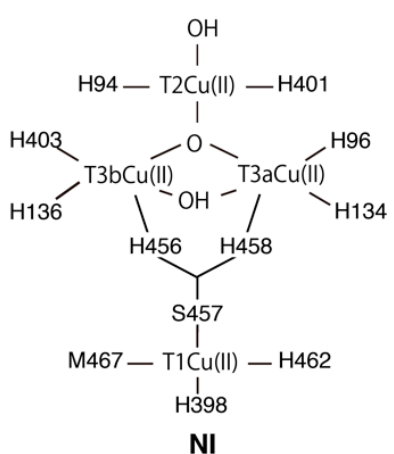

Figure 1. Schematic illustration of the proposed TNC intermediate states of BOD in the entire catalytic cycle. The calculated states were the native intermediate (NI), resting oxidized state in two different protonation states $\left(\mathrm{RO}_{0}\right.$ and $\left.\mathrm{RO}_{1}\right)$, and fully reduced states with and without a bridging water molecule $\left(\mathrm{FR}_{\mathrm{W}}\right.$ and FR).

We are particularly interested in characterizing the structural changes upon the four-electron reduction processes $\mathrm{NI} \rightarrow \mathrm{FR}$ and $\mathrm{RO} \rightarrow \mathrm{FR}$ within the $\mathrm{BOD}$ catalytic cycle. These processes are expected to be deeply related to the entire catalytic cycle and relative redox potential requirements for the $\mathrm{T} 1 \mathrm{Cu}$ and TNC. We expected that these rules and functional features would provide important insights into the BOD catalytic activities and applications of BOD.

Recently, we reported that the wild-type (WT) BOD possesses a characteristic cross-link between Trp396 and His398, which directly coordinates to the T1Cu [10]. Met467 is another T1Cu coordinating residue that can be mutated to alter the redox potential of $\mathrm{T} 1 \mathrm{Cu}$. In the M467Q mutant, the Trp396-His398 cross-link is lost [10] and the catalytic activity becomes quite low $(\sim 0.3 \%)[11,12]$. Therefore, we intend to examine theoretically how the mutation influences the electronic structures of 
T1Cu and TNC. In the present study, the quantum mechanics/molecular mechanics (QM/MM) method was employed to elucidate the geometrical changes and electronic states of T1Cu and TNC. For the QM region, the unrestricted hybrid density functional theory was adapted to describe the open-shell system (Figure 2). We have demonstrated that the QM/MM approach is handy and powerful enough to be used for open shell systems with transition metal centers [13-16]. Therefore, we adapted the QM/MM methodology with a large QM region, and the electronic structure analyses based on the natural orbitals, atomic spin densities and molecular orbitals have been performed in the present study.
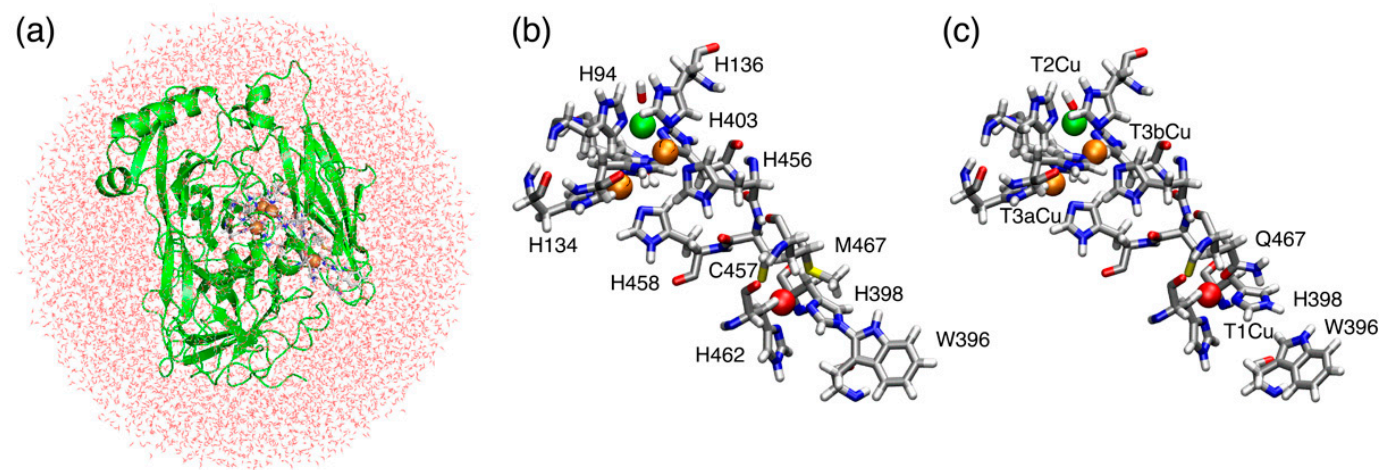

Figure 2. (a) Overall view of the QM/MM system used in the present study. (b) QM region in the wild-type (WT). (c) QM region in the M467Q mutant. The green, orange and red spheres represent the $\mathrm{T} 2 \mathrm{Cu}, \mathrm{T} 3 \mathrm{Cu}$ and $\mathrm{T} 1 \mathrm{Cu}$ atoms, respectively.

\section{Results and Discussions}

\section{1. $T 1 C u$}

The $\mathrm{T} 1 \mathrm{Cu}$ is coordinated by four amino acid residues, His398, Cys457, His462, and Met467. In the oxidized state such as $\mathrm{RO}_{0}$, the $\mathrm{QM} / \mathrm{MM}$ optimized $\mathrm{T} 1 \mathrm{Cu}(\mathrm{II})-\mathrm{S}$ (Met467) distance is $R(\mathrm{~T} 1 \mathrm{Cu}(\mathrm{II})$, $\mathrm{S}($ Met467) $)=3.23 \AA$, which is longer compared to the other coordination distances; $R(\mathrm{~T} 1 \mathrm{Cu}(\mathrm{II})$, $\mathrm{N}($ His398) $)=2.01 \AA, R(\mathrm{~T} 1 \mathrm{Cu}(\mathrm{II}), \mathrm{N}($ His462) $)=1.98 \AA$, and $R(\mathrm{~T} 1 \mathrm{Cu}(\mathrm{II}), \mathrm{S}(\mathrm{Cys} 457))=2.17 \AA$. The coordination geometry of $\mathrm{T} 1 \mathrm{Cu}$ is trigonal-pyramidal, where the atoms in the two His and Cys residues form an equatorial triangle and the $S$ atom in Met467 defines the axial coordination. As shown in Figure 3a, the localized singly occupied natural orbital (LSONO) [17] for the T1Cu is composed of the $\mathrm{Cu} \mathrm{d}_{\mathrm{x} 2-\mathrm{y} 2}$ orbital and $2 \mathrm{p}$ orbital of the Cys457 S atom. The calculated Löwdin atomic spin densities $(\rho(\mathrm{S}(\mathrm{Cys} 457))=0.53$ and $\rho(\mathrm{T} 1 \mathrm{Cu})=0.34)$ also show a large spin/unpaired electron orbital distribution over the T1Cu and S of Cys457 (Table 1).

In the reduced state, such as the FR state, $\mathrm{T} 1 \mathrm{Cu}$ becomes $\mathrm{Cu}(\mathrm{I})$, and the atomic spin densities are not observed over the T1Cu and S of Cys457. The coordination distances around the T1Cu slightly increased as $R(\mathrm{~T} 1 \mathrm{Cu}(\mathrm{I}), \mathrm{S}(\operatorname{Met} 467))=3.44(+0.21) \AA, R(\mathrm{~T} 1 \mathrm{Cu}(\mathrm{I}), \mathrm{N}($ His398) $)=2.19(+0.18) \AA, R(\mathrm{~T} 1 \mathrm{Cu}(\mathrm{I})$, $\mathrm{N}($ His462) $)=2.00(+0.02) \AA$, and $R(\mathrm{~T} 1 \mathrm{Cu}(\mathrm{I}), \mathrm{S}(\mathrm{Cys} 457))=2.20(+0.03) \AA$, in which the distance changes upon the reduction are shown in parentheses. These very small structural changes match to minimize the reorganization energy during the electron transfer via the $\mathrm{T} 1 \mathrm{Cu}$ site. These small structural changes can be attributed to the large spin-orbital delocalization from the d orbital of T1Cu to the p orbital of $S$ of Cyc457.

The corresponding coordination distances around the $\mathrm{T} 1 \mathrm{Cu}$ in the $\mathrm{X}$-ray structure $(\mathrm{PDBID}=$ 6IQZ) [10] are $R(\mathrm{~T} 1 \mathrm{Cu}, \mathrm{S}(\mathrm{Met} 467))=3.36(-0.08) \AA, R(\mathrm{~T} 1 \mathrm{Cu}, \mathrm{N}($ His398) $)=2.06(-0.13) \AA, R(\mathrm{~T} 1 \mathrm{Cu}$, $\mathrm{N}($ His462) $)=2.05(+0.05) \AA$, and $R(\mathrm{~T} 1 \mathrm{Cu}, \mathrm{S}(\mathrm{Cys} 457))=2.16(-0.04) \AA$, in which the differences to the $\mathrm{QM} / \mathrm{MM}$ optimized structure in the $\mathrm{T} 1 \mathrm{Cu}(\mathrm{I})$ state are given in parentheses. These results indicated that these coordination distances are properly reproduced by the present QM/MM calculations within $0.1 \AA$ A. 

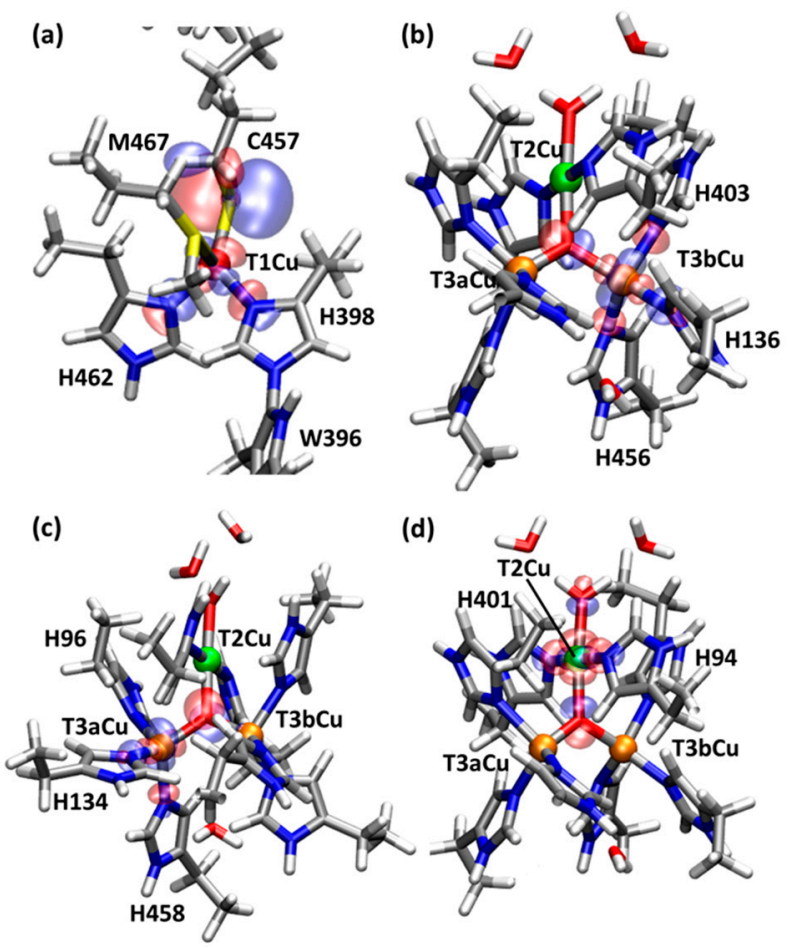

Figure 3. Localized singly occupied natural orbitals (LSONOs) calculated at $\mathrm{RO}_{0}$, which contain four $\mathrm{d}$ orbitals mainly localizing on each Cu center ((a) T1, (b) T2, (c) T3a and (d) T3b). For clarity, the pictures are enlarged only for the part of the orbital distribution.

Table 1. Calculated Löwdin atomic spin densities.

\begin{tabular}{cccccccc}
\hline & T1Cu & S (C457) & T2Cu & T3aCu & T3bCu & $\boldsymbol{\mu}^{3}$-oxo & $\boldsymbol{\mu}^{2}$-OH/W \\
\hline $\mathrm{NI}$ & 0.00 & 0.00 & 0.59 & 0.64 & 0.66 & 1.07 & 0.28 \\
$\mathrm{NI}{ }^{\mathrm{H}+}$ & 0.13 & 0.30 & 0.58 & 0.62 & 0.65 & 0.75 & 0.29 \\
$\mathrm{RO}_{\mathrm{W}}$ & 0.30 & 0.55 & 0.59 & 0.46 & 0.65 & 0.76 & 0.08 \\
$\mathrm{RO}_{0}$ & 0.31 & 0.57 & 0.62 & 0.53 & 0.65 & 0.63 & - \\
$\mathrm{RO}_{1}$ & 0.32 & 0.57 & 0.50 & 0.56 & 0.60 & - & 0.22 \\
$\mathrm{FR}_{W}$ & 0.00 & 0.00 & 0.00 & 0.00 & 0.00 & - & 0.00 \\
$\mathrm{FR}$ & 0.00 & 0.00 & 0.00 & 0.00 & 0.00 & - & - \\
\hline
\end{tabular}

\section{2. $\mathrm{T} 2 \mathrm{Cu}$ and $\mathrm{T} 3 \mathrm{Cu}$}

The $\mathrm{T} 2 \mathrm{Cu}$ is coordinated to two His residues, His94 and His401, and one water (W) or hydroxo $(\mathrm{OH})$ ligand. In the states from the $\mathrm{NI}$ to $\mathrm{RO}_{0}$, the $\mu^{3}$-oxo atom additionally coordinates to TNC, and $\mathrm{T} 2 \mathrm{Cu}$ is coordinated by the four ligands in a square planar orientation. On the other hand, the T3Cu atoms are both coordinated to three His residues and the $\mu^{3}$-oxo atom, and these ligands form a tetrahedral coordination. As shown in Figure 1, the NI, $\mathrm{RO}_{1}$ and $\mathrm{FR}_{\mathrm{W}}$ states contain $\mu^{2}$-hydroxyl/water bridges between the pair of $\mathrm{T} 3 \mathrm{Cu}$ ions. In the $\mathrm{RO}_{1}, \mathrm{FR}_{\mathrm{W}}$ and $\mathrm{FR}$ states, there are no directly bridging ligands between the $\mathrm{T} 2 \mathrm{Cu}$ and $\mathrm{T} 3 \mathrm{Cu}$ atoms. In all these states, three $\mathrm{Cu}$ atoms of TNC are arranged in a triangle, which will be suitable for the four-electron reduction of $\mathrm{O}_{2}$ to occur at the central position during the FR to NI transition. In the oxidized states (NI and $\mathrm{RO}$ ), all the $\mathrm{T} 1 \mathrm{Cu}, \mathrm{T} 2 \mathrm{Cu}$ and $\mathrm{T} 3 \mathrm{Cu}$ ions are expected to be $\mathrm{Cu}(\mathrm{II})$. In the fully reduced states $\left(\mathrm{FR}_{\mathrm{W}}\right.$ and $\left.\mathrm{FR}\right)$, all the $\mathrm{Cu}$ ions are expected to be $\mathrm{Cu}(\mathrm{I})$. Two states with and without the $\mu^{2}$-water between two T3Cu ions were examined. These states are called $\mathrm{FR}_{\mathrm{W}}$ and FR, respectively.

In the NI state, the calculated Löwdin atomic spin densities are $\rho(\mathrm{T} 1 \mathrm{Cu})=0.00, \rho(\mathrm{S}(\mathrm{Cys} 457))$ $=0.00$ and $\rho\left(\mu^{3}\right.$-oxo $)=1.07$ (Table 1$)$. This result indicated that TNC in the NI state is one more oxidized with the $\mu^{3}$-oxo radical, while the $\mathrm{T} 1 \mathrm{Cu}$ is one-electron reduced with $\mathrm{Cu}(\mathrm{I})$. The use of 
different DFT exchange-correlation functionals, such as BLYP and BHLYP, does not affect/improve the one-electron transfer from TNC to T1Cu. This means that $\mathrm{T} 1 \mathrm{Cu}(\mathrm{I})$ cannot reduce the TNC, and this NI state is unstable. Therefore, other protonation states during the NI to RO transition are examined and compared. As illustrated in Figure 4, there are two intermediate states after the first and second protonations for $\mathrm{NI}$, and they are called $\mathrm{NI}^{\mathrm{H}+}$ and $\mathrm{RO}_{\mathrm{W}}$, respectively.

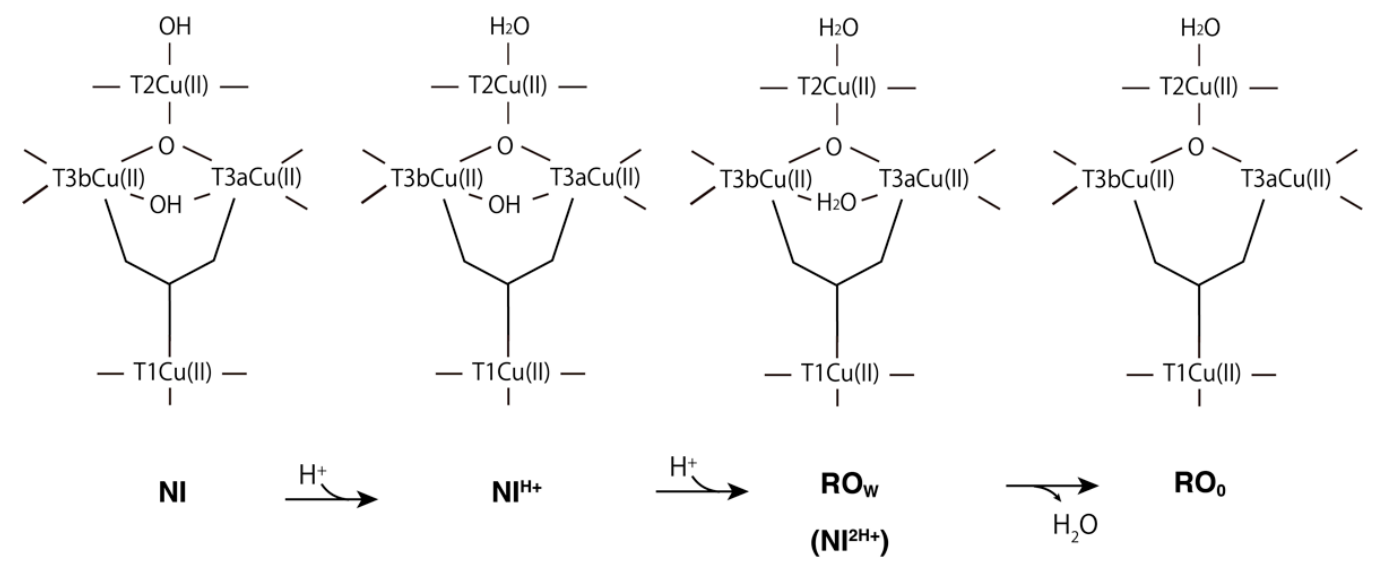

Figure 4. Intermediate states for the NI and RO states. The order of the two-step protonation and the subsequent water elimination is proposed as shown in this scheme. The first and second intermediate states are noted as $\mathrm{NI}^{\mathrm{H}+}$ and $\mathrm{RO}_{\mathrm{W}}$, respectively.

For the first protonated state, $\mathrm{NI}^{\mathrm{H}+}$, there are two possible protonation sites at the $\mathrm{OH}$ of $\mathrm{T} 2 \mathrm{Cu}$ or at the $\mu^{2}-\mathrm{OH}$ between the $\mathrm{T} 3 \mathrm{Cu}$ ions. The former $\mathrm{NI}^{\mathrm{H}+}$ state, which is illustrated in Figure 4, is more stable than the latter one by $34.1 \mathrm{kcal} \mathrm{mol}^{-1}$. Thus, the $\mathrm{OH}$ of $\mathrm{T} 2 \mathrm{Cu}$ is protonated first, and $\mu^{2}-\mathrm{OH}$ of the $\mathrm{T} 3 \mathrm{Cu}$ ions is then protonated to $\mathrm{RO}_{\mathrm{W}}$ in the subsequent protonation as illustrated in Figure 4. The energy difference for the first and second protonations is $\Delta \Delta E=\left(\Delta E(\mathrm{NI})-\Delta E\left(\mathrm{NI}^{\mathrm{H}+}\right)\right)-\left(\Delta E\left(\mathrm{NI}^{\mathrm{H}+}\right)\right.$ $\left.-\Delta E\left(\mathrm{RO}_{\mathrm{W}}\right)\right)=41.8 \mathrm{kcal} \mathrm{mol}^{-1}$. This indicated that the second protonation step is more difficult. This result is consistent with the reaction rate via $\mathrm{RO}$ of $k=0.05 \mathrm{~s}^{-1}$ and this reaction is very slow compared to the catalytic reaction of $k=350 \mathrm{~s}^{-1}$, in which the direct route is adapted without forming $\mathrm{RO}$ [6]. As the energy barrier expected for the NI to RO transition corresponds to $8.8-13.9 \mathrm{kcal} \mathrm{mol}^{-1}$, we can estimate that the first protonation step to $\mathrm{NI}^{\mathrm{H}+}$ can spontaneously occur. Another possibility is that the deprotonation of the water ligand of $\mathrm{T} 2 \mathrm{Cu}$ did not occur during the PI state formation.

The atomic spin densities at $\mathrm{NI}^{\mathrm{H}+}$ are $\rho(\mathrm{T} 1 \mathrm{Cu})=0.13, \rho(\mathrm{S}(\mathrm{Cys} 457))=0.30$ and $\rho\left(\mu^{3}\right.$-oxo $)=0.75$, $\left.\rho\left(\mathrm{O} \mu^{2}-\mathrm{OH}\right)\right)=0.29$. These atomic spin densities at the $\mathrm{T} 1 \mathrm{Cu}$ indicate that $\mathrm{T} 1 \mathrm{Cu}$ is in a half-reduced-like $\mathrm{Cu}(1.5)$ oxidation state. It also suggests that $\mathrm{T} 1 \mathrm{Cu}$ can reduce the $\mathrm{TNC}$ when $\mathrm{T} 1 \mathrm{Cu}$ is further reduced. Based on these $\mathrm{QM} / \mathrm{MM}$ results, we expect that $\mathrm{NI}^{\mathrm{H}+}$ is one candidate for the stable native intermediate.

The $\mathrm{RO}_{\mathrm{W}}$ generated after the second protonation contains a water molecule which is almost dissociated from the $\mathrm{T} 3 \mathrm{aCu}\left(R\left(\mathrm{~T} 3 \mathrm{aCu}, \mathrm{O}_{\mathrm{W}}\right)=2.58 \AA\right)$. Therefore, after the release of the water molecule, the $\mathrm{RO}$ state will be formed easily. In the $\mathrm{RO}_{\mathrm{W}}$ state, $\mathrm{T} 1 \mathrm{Cu}$ is almost in the $\mathrm{Cu}(\mathrm{II})$ state based on the atomic spin densities $\left(\rho(\mathrm{T} 1 \mathrm{Cu})=0.30, \rho(\mathrm{S}(\mathrm{Cys} 457))=0.55, \rho\left(\mu^{3}\right.\right.$-oxo $\left.)=0.76, \rho\left(\mathrm{O}\left(\mu^{2}-\mathrm{W}\right)\right)=0.08\right)$. These results mean that TNC in the $\mathrm{RO}_{\mathrm{W}}$ state becomes very oxidative after the two-step protonation.

For the next RO state, two possible states with $\mu^{3}-\mathrm{OH}$ or with $\mu^{3}$-oxo were examined. We found that the $\mu^{3}$-oxo form is more stable than the $\mu^{3}-\mathrm{OH}$ form by $24.9 \mathrm{kcal} \mathrm{mol}^{-1}$. Therefore, the former state with $\mu^{3}-\mathrm{OH}$, called $\mathrm{RO}_{0}$ should be the proper $\mathrm{RO}$ state compared to the latter state with $\mu^{3}$-oxo, called $\mathrm{RO}_{1}$, at the present $\mathrm{QM} / \mathrm{MM}$ theoretical level. The Löwdin atomic densities are $\rho(\mathrm{T} 1 \mathrm{Cu})=0.31$ $(0.32), \rho(\mathrm{T} 2 \mathrm{Cu})=0.62(0.50), \rho(\mathrm{T} 3 \mathrm{aCu})=0.53(0.56)$, and $\rho(\mathrm{T} 3 \mathrm{bCu})=0.65(0.60)$ for $\mathrm{RO}_{0}\left(\mathrm{RO}_{1}\right)$. Thus, all the T1-, T2- and $\mathrm{T} 3 \mathrm{Cu}$ atoms in the $\mathrm{RO}$ states become close to the $\mathrm{Cu}(\mathrm{II})$ formal oxidation states. 
The localized singly-occupied natural orbitals (LSONOs) [17] for the d orbitals of TNC are shown in Figure $3 b-d$.

As the calculated Löwdin atomic spin densities on the $\mathrm{Cu}$ atoms are zero in both FR and FR states, the $\mathrm{Cu}$ atoms can be considered as $\mathrm{Cu}(\mathrm{I})$. Structural changes upon the reduction are mainly observed for the $\mathrm{Cu}$ positions, and the triangle formed by the three $\mathrm{Cu}$ atoms in TNC is enlarged due to the removal of the central $\mu^{3}$-oxo (Table 2). The distances become $R(\mathrm{~T} 2 \mathrm{Cu}-\mathrm{T} 3 \mathrm{aCu})=4.34 \AA(+0.86)$, $R(\mathrm{~T} 2 \mathrm{Cu}-\mathrm{T} 3 \mathrm{bCu})=4.52 \AA(+1.04)$, and $R(\mathrm{~T} 3 \mathrm{aCu}-\mathrm{T} 3 \mathrm{bCu})=4.79 \AA(+1.52)$ in $\mathrm{FR}_{\mathrm{W}}$, where the distance changes compared to the $\mathrm{RO}_{0}$ are shown in parentheses. After the elimination of the $\mu^{2}$-water between the $\mathrm{T} 3 \mathrm{Cu}$ atoms, the $\mathrm{Cu}-\mathrm{Cu}$ distances slightly shrink to $4.27,4.45$, and $4.60 \AA$, respectively. Therefore, the $\mu^{2}$-water contributes slightly to elongating the T3Cu atoms. The binding energy of the $\mu^{2}$-water is calculated to be $26.5 \mathrm{kcal} \mathrm{mol}^{-1}$. The solvation energy of the water molecule is much higher compared to the binding energy. Then the $\mu^{2}$-water will be easily released to the solvent.

Table 2. Key atomic distances for the TNC $(R / \AA)$.

\begin{tabular}{|c|c|c|c|c|c|}
\hline & $\mathrm{T} 2 \mathrm{Cu}-\mathrm{T} 3 \mathrm{aCu}$ & $\mathrm{T} 2 \mathrm{Cu}-\mathrm{T} 3 \mathrm{bCu}$ & $\mathrm{T} 3 \mathrm{aCu}-\mathrm{T} 3 \mathrm{bCu}$ & $\begin{array}{c}\mathrm{Cu}-\mu^{3}-\text { oxo }(\mathrm{T} 2 \mathrm{Cu}, \\
\text { T3aCu, T3bCu) }\end{array}$ & $\begin{array}{c}\mathrm{Cu}-\mu^{2}-\mathrm{OH} / \mathrm{W} \\
(\mathrm{T} 3 \mathrm{aCu}, \mathrm{T} 3 \mathrm{bCu})\end{array}$ \\
\hline $\mathrm{NI}$ & 3.84 & 3.75 & 3.14 & $2.07,2.18,2.02$ & $1.94,1.90\left(\mu^{2} \mathrm{OH}\right)$ \\
\hline $\mathrm{NI}^{\mathrm{H}+}$ & 3.60 & 3.56 & 3.06 & $1.94,1.99,2.07$ & $1.95,1.90\left(\mu^{2} \mathrm{OH}\right)$ \\
\hline $\mathrm{RO}_{\mathrm{W}}$ & 3.52 & 3.59 & 3.38 & $2.03,1.94,2.11$ & $2.58,1.99\left(\mu^{2} W\right)$ \\
\hline $\mathrm{RO}_{0}$ & 3.48 & 3.48 & 3.27 & $2.09,1.94,1.89$ & - \\
\hline $\mathrm{RO}_{1}$ & 4.28 & 4.21 & 3.66 & - & $1.99,1.93\left(\mu^{2} \mathrm{OH}\right)$ \\
\hline $\mathrm{FR}_{\mathrm{W}}$ & 4.34 & 4.52 & 4.79 & - & $2.45,2.46\left(\mu^{2} W\right)$ \\
\hline FR & 4.27 & 4.45 & 4.60 & - & - \\
\hline 2XLL & 4.06 & 4.07 & 4.87 & - & - \\
\hline 6IQZ & 4.18 & 3.98 & 4.98 & - & $2.69,2.29$ \\
\hline 3UAA & 3.65 & 3.61 & 3.22 & $1.83,2.07,2.27$ & $2.06,1.82$ \\
\hline 3UAE & 4.40 & 3.98 & 4.96 & - & $2.77,2.27$ \\
\hline
\end{tabular}

The characteristic structural change in TNC upon reduction is mainly attributed to the loss of the $\mu^{3}$-oxo in the oxidized forms (NI-RO). Therefore, we propose that the percentage of the reduction of the TNC will be proportional to the square root of the area spanned by the T2Cu and T3Cu atoms.

The area of a triangle with three side lengths $\left(l_{12}, l_{23}, l_{31}\right)$ is easily calculated using Heron's formula.

$$
\begin{gathered}
S_{\text {triangle }}=\sqrt{s\left(s-l_{12}\right)\left(s-l_{23}\right)\left(s-l_{31}\right)} \\
s=\left(l_{12}+l_{23}+l_{31}\right) / 2
\end{gathered}
$$

One side length $l$ assumed in an ideal equilateral triangle is calculated as

$$
l=\sqrt{\frac{4 S}{\sqrt{3}}}
$$

This equation can be derived from

$$
S=\frac{\sqrt{3}}{4} l^{2}
$$

As the $l$ value becomes close to the actual $\mathrm{Cu}-\mathrm{Cu}$ lengths, this index $l$ is very meaningful and useful to characterize the structural features of TNC.

For the oxidized states such as the NI, $\mathrm{NI}^{\mathrm{H}+}, \mathrm{RO}_{\mathrm{W}}$ and $\mathrm{RO}_{0}$ states, the $l$ values are $3.4-3.5 \AA$. For the reduced states, such as the FR $\mathrm{W}_{\mathrm{W}}$ and FR states, the $l$ values are $4.4-4.5 \AA$ (Table 3). The $l$ values for the X-ray structures of MCOs are in the range of 4.3-4.4 $\AA$ except for the $3.5 \AA$ of PDBID = 3UAA. The 3UAA is the only structure which processes the $\mu^{3}$-oxo, and it is solved as an oxidized state. Based on the root mean square deviation (RMSD), most of the X-ray structures (PDBIDs = 2XLL [3], 6IQZ [10], 
3UAE [18]) are closest to the $\mathrm{FR}_{\mathrm{W}}$ state except for the 3UAA structure [18], which is closest to the $\mathrm{NI}^{\mathrm{H}+}$ state. Therefore, the index $l$ is a very useful parameter which represents the oxidation state of the TNC. It should be noted that the index $l$ will be valuable to estimate the percentage of the reduced state of the X-ray crystal structures by interpolating between $l_{\mathrm{ox}}=3.382 \AA$ and $l_{\text {red }}=4.538 \AA$, in which we assume that the oxidized $(\mathrm{OX})$ and reduced (red) states are presented by the $\mathrm{NI}^{\mathrm{H}+}$ and $\mathrm{FR}_{\mathrm{W}}$ states, respectively.

$$
\begin{gathered}
l=C_{o x} l_{o x}+\left(1-C_{o x}\right) l_{r e d} \\
C_{o x}=\frac{l_{r e d}-l}{l_{\text {red }}-l_{o x}}
\end{gathered}
$$

Using Equation (6), the TNCs of 3UAA and 3UAE are estimated to be $92 \%$ and $12 \%$ oxidized states, respectively. The X-ray structures of 3UAA and 3UAE were taken under the low and high X-ray dose conditions for the $\mathrm{Cu}$ efflux Oxidase (CueO), respectively, and the latter data are more reduced by the X-ray exposure [18]. Therefore, the estimation using Equation (6) provides a reasonable prediction for the oxidation level of TNC.

The X-ray structure of 3UAE shows a very low electron density around the $\mu^{2}-\mathrm{O}$ atom position, which was assigned to the oxygen atom of $\mu^{2}$-water in the FR $\mathrm{W}_{\mathrm{W}}$ state. Based on the RMSD values, the structure of 3UAE most closely resembles the optimized structure in the FRW state which agrees with the past experimental assignment [18]. For PDBID $=6 \mathrm{IQZ}$, the TNC is closest to the FR $\mathrm{W}_{\mathrm{W}}$ state based on the RMSD values. This assignment is appropriate because the electron density around the $\mu^{2}-\mathrm{O}$ atom position was observed, which limits the candidates to $\mathrm{RO}_{1}$ and $\mathrm{FR}_{\mathrm{W}}$. Based on the present theoretical study, we showed that $\mathrm{RO}_{1}$ is very unstable compared to $\mathrm{RO}_{0}$. Therefore, the TNC of $6 \mathrm{IQZ}$ is assigned not to $\mathrm{RO}_{1}$ but to $\mathrm{FR}_{\mathrm{W}}$.

Table 3. Similarities (in $\AA$ unit) of TNC among all the calculated states and X-ray structures. ${ }^{\text {a }}$

\begin{tabular}{cccccc}
\hline & $\boldsymbol{l}$ & RMSD (2XLL) & RMSD (6IQZ) & RMSD (3UAA) & RMSD (3UAE) \\
\hline $\mathrm{NI}$ & 3.538 & 0.716 & 0.766 & 0.105 & 0.749 \\
$\mathrm{NI}^{\mathrm{H}+}$ & 3.382 & 0.720 & 0.766 & $\underline{0.051}$ & 0.765 \\
$\mathrm{RO}_{\mathrm{W}}$ & 3.493 & 0.610 & 0.654 & 0.097 & 0.669 \\
$\mathrm{RO}_{0}$ & 3.405 & 0.658 & 0.702 & 0.088 & 0.713 \\
$\mathrm{RO}_{1}$ & 4.023 & 0.566 & 0.614 & 0.327 & 0.579 \\
$\mathrm{FR}_{W}$ & 4.538 & $\underline{0.232}$ & $\underline{0.245}$ & 0.683 & $\underline{0.257}$ \\
$\mathrm{FR}$ & 4.433 & 0.245 & 0.270 & 0.606 & 0.282 \\
$2 \mathrm{XLL}$ & 4.278 & 0 & 0.073 & 0.674 & 0.147 \\
$6 \mathrm{IQZ}$ & 4.309 & 0.073 & 0 & 0.721 & 0.202 \\
3UAA & 3.477 & 0.674 & 0.721 & 0 & 0.719 \\
3UAE & 4.394 & 0.147 & 0.202 & 0.719 & 0 \\
\hline
\end{tabular}

a Underlines for the RMSD emphasize the smallest/closest data sets to the X-ray structures.

\subsection{Molecular Orbital Analysis for the Reduction Process of WT and M467Q BOD}

Changes in molecular orbitals for the $\mathrm{Cu}$ centers were analyzed and the orbital energy levels are shown in Figure 5. In the oxidized state of NI, the $\beta$ highest occupied molecular orbital $(\beta \mathrm{HOMO})$ is mainly the $p$ orbital of the $\mu^{3}$-oxo, and the $\beta$ lowest unoccupied molecular orbital ( $\beta$ LUMO) is mainly localized on the T1Cu and S of Cys457, which is consistent with the spin density distribution. After the first protonation, in the $\mathrm{NI}^{\mathrm{H}+}$ state, the $\beta \mathrm{HOMO}$ and $\beta \mathrm{LUMO}$ are mixed together, and the orbital energies of the $\beta \mathrm{HOMO}, \beta \mathrm{LUMO}$ and higher $\beta \mathrm{LUMO}$ for T2Cu and T3Cu ions become more stabilized. The higher $\beta$ LUMOs are highly delocalized over the TNC. The orbital energy levels in Figure 5 clearly show that $\mathrm{T} 1 \mathrm{Cu}$ is more easily reduced than the TNC. After the second protonation to $\mathrm{RO}_{0}$, the LUMOs become further stabilized and the $\mathrm{Cu}$ centers become more reducible. The orbital energy level for the T1Cu ( $\beta$ LUMO) is lowered from $-0.726 \mathrm{eV}$ to $-2.981 \mathrm{eV}$, i.e., by $-2.255 \mathrm{eV}$ during the $\mathrm{NI}^{\mathrm{H}+}$ to $\mathrm{RO}_{0}$ state transition (All the numerical data for these orbitals are summarized in the 
supporting information, Tables S1 and S2). The average orbital energies for the TNC higher $\beta$ LUMOs become $2.922 \mathrm{eV}, 1.232 \mathrm{eV}$ and $-1.425 \mathrm{eV}$ in the $\mathrm{NI}, \mathrm{NI}^{\mathrm{H}+}$ and $\mathrm{RO}_{0}$ states, respectively, i.e., they are stabilized by $-1.689 \mathrm{eV}$ and $-2.658 \mathrm{eV}$ by the protonation steps. The $\beta L U M O$ s for the $\mathrm{Cu}$ atoms are shown in Figure 6.

In the reduced states of $\mathrm{FR}$ and $\mathrm{FR}_{\mathrm{W}}$, the $\mathrm{d}$ orbitals for $\mathrm{T} 1 \mathrm{Cu}$ and $\mathrm{TNC}$ are all occupied; the $\beta$ HOMO corresponds to the $\mathrm{d}$ orbital of $\mathrm{T} 1 \mathrm{Cu}$ and the lower $\beta$ HOMOs contain the $\mathrm{d}$ orbital components for TNC. The orbital energies for FR and FR $\mathrm{W}_{W}$ indicate that the $\beta^{2}$-water coordination does not perturb these $\beta$ HOMOs. In FR and $\mathrm{FR}_{W}$, the $\beta \mathrm{HOMO}$ of the $\mathrm{T} 1 \mathrm{Cu}$ lies slightly above or almost level with the $\beta \mathrm{HOMO}-1$ of T3Cu. This means that the redox potential of the T1Cu of the WT is maximized to reduce the TNC.

The corresponding orbital energies of the $\mathrm{M} 467 \mathrm{Q}$ mutant are all increased. For example, in $\mathrm{RO}_{0}$, the $\beta L U M O$ for T1Cu and the average for the TNC higher $\beta$ LUMOs are $-1.927 \mathrm{eV}$ and $-1.003 \mathrm{eV}$, which are increased by $1.053 \mathrm{eV}$ and $0.422 \mathrm{eV}$, respectively. In $\mathrm{FR}_{\mathrm{W}}$, the $\beta \mathrm{HOMO}$ for $\mathrm{T} 1 \mathrm{Cu}$ and the average for the TNC lower $\beta$ HOMOs are $2.099 \mathrm{eV}$ and $1.340 \mathrm{eV}$, which are increased by $1.378 \mathrm{eV}$ and $0.383 \mathrm{eV}$, respectively. Therefore, a consequence of the mutation is the increase of the T1Cu as well as the TNC orbital energies. The upshift of the T1Cu orbital energy level in the M467Q mutant is consistent with the decrease in the $\mathrm{T} 1 \mathrm{Cu}$ redox potential from $470 \mathrm{mV}$ to $270 \mathrm{mV}$ in the M467Q mutant [12], which contributes to slowing down the electron transfer from bilirubin to T1Cu. It should be noted again that the lower shift of the T1Cu orbital is not permitted because it must be higher than the orbital levels of TNC. In this sense, the redox potential of T1Cu is optimized in the WT BOD to catalyze the bilirubin oxidation.
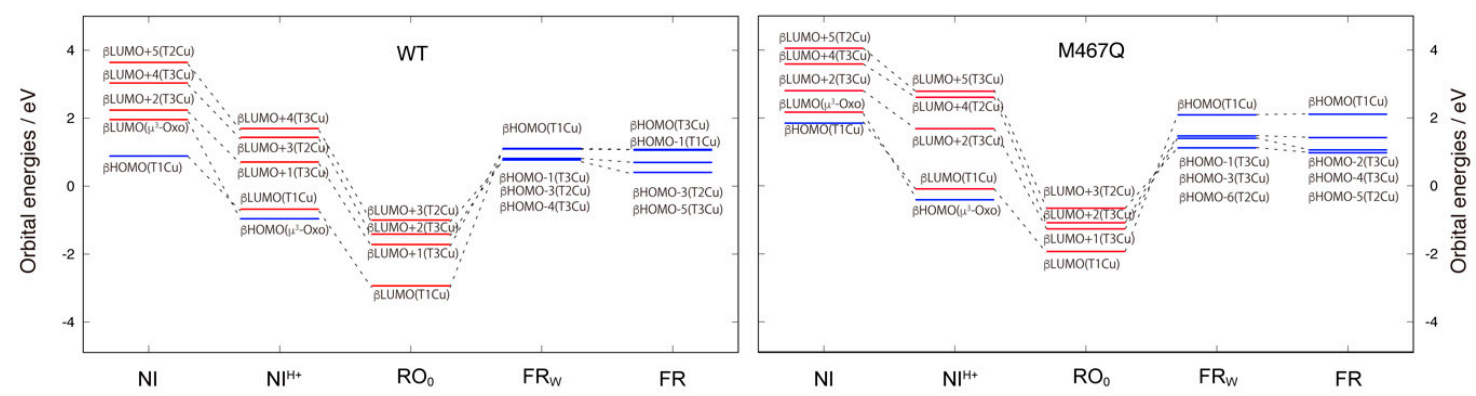

Figure 5. $\beta$ molecular orbital energies of the WT and M467Q models.

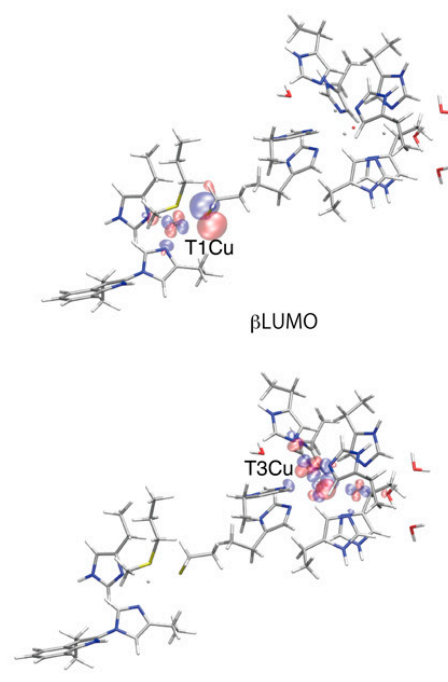

$\beta L U M O+2$
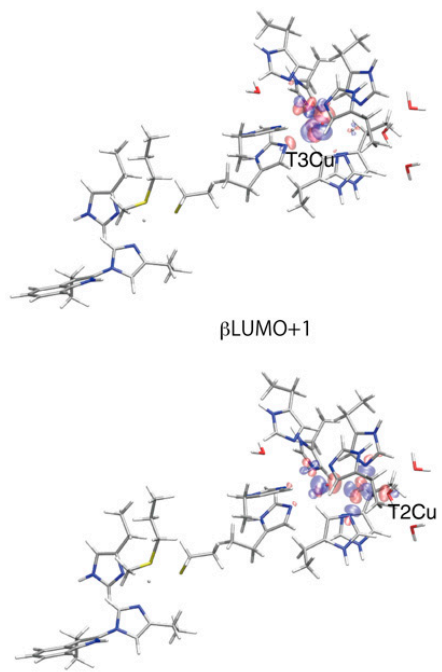

$\beta L U M O+3$

Figure 6. $\beta$ unoccupied molecular orbitals calculated at the $\mathrm{RO}_{0}$ in WT. These MOs are similar to the LSONOs shown in Figure 3, and these MOs are doubly occupied in the FR states. 


\section{Materials and Methods}

\section{Computational Details}

The QM/MM calculations were performed using the NWChem program package (version 6.3) (Pacific Northwest National Laboratory, Richland, WA, USA) [19]. The unrestricted density functional theory with the B3LYP exchange-correlation functional [20] and the Grimme's D3 dispersion correction (UB3LYP-D3) [21] were used for the QM region, and the rest of the MM region was applied to the AMBER-99 force field [22]. Basis sets used for the copper and the other atoms were LanL2DZ (Los Alamos ECP plus DZ) and 6-31G(d), respectively [23-26]. The initial coordinates of the WT BOD (PDBID: 6IQZ) and M467Q mutant (PDBID: 6IQY) were taken from their high-resolution X-ray structures determined at 1.46 and $1.60 \AA$ resolutions, respectively [10]. The BODs from fungus Myrothecium verrucaria were produced in Pichia pastoris as recombinant proteins. The PROPKA program (GitHub, San Francisco, CA, USA) [27,28] was employed to estimate the protonation states of the titratable residues (Asp, Glu, His, Lys, and Arg). The BODs were neutralized by $12 \mathrm{Na}^{+}$ions and were solvated by MM water molecules in a sphere of $90 \AA$ diameter (Figure 2a). First, energy minimization for the hydrogen atom was performed at the MM level. Next, a 10 ps MD simulation at $298.15 \mathrm{~K}$ was performed to relax all the hydrogen atoms, solvent water molecules and $\mathrm{Na}$ ions. After another 10 ps cooling from $298.15 \mathrm{~K}$ to $0 \mathrm{~K}$, a 1000-step energy minimization was performed under the same constraint condition. Therefore, coordinates of the heavy atoms are the same in the X-ray structures and all the atoms added to construct the theoretical model were redistributed properly. For the non-bonded QM-MM interactions, electron embedding schemes with a $9 \AA$ cut-off and with no cut-off were used for the geometric optimizations and energy minimization calculations, respectively. The QM region contains the $\mathrm{T} 1 \mathrm{Cu}, \mathrm{T} 2 \mathrm{Cu}$ and $2 \mathrm{~T} 3 \mathrm{Cu}$ atoms, 3 water molecules, and the 13 nearest amino acid residues (His94, His96, His134, His136, Trp396, His398, His401, His403, His456, Cys457, His458, His462, and Met467 in WT BOD/Gln467 in M467Q BOD) (Figure 2b,c). Especially, S of Cys457 was assumed to be deprotonated. The hydrogen link atom approach was used for treating the QM/MM boundary. The entire model contains about 38,000 atoms (about 10,000 molecules), while the QM region contains about 210 atoms. As we adapted a large QM region, the electronic structure of the QM/MM model is accurate enough by minimizing the artificial effect from the hydrogen link atoms. The molecular structures and molecular orbitals shown in the figures were drawn using PyMOL (DeLano Scientific LLC, Palo Alto, CA, USA.) $[29,30]$ and the visual molecular dynamics (VMD) program (Theoretical and Computational Biophysics Group, Urbana, IL, USA) [31]. Complete numerical data for the QM/MM optimized structures and orbital energies are available in the Supplementary Materials.

\section{Conclusions}

The catalytic intermediates of BOD: $\mathrm{NI}, \mathrm{NI}^{\mathrm{H}+}, \mathrm{RO}_{\mathrm{W}}, \mathrm{RO}, \mathrm{FR}_{\mathrm{W}}$ and $\mathrm{FR}$, were investigated using the QM/MM method. The characteristic structural changes for the T1Cu and TNC are discussed for each intermediate state, and their spin distributions and the molecular orbital levels were precisely analyzed. In the NI state, the $\mathrm{T} 1 \mathrm{Cu}(\mathrm{I})$ and excessively oxidized TNC state were calculated, which is very high in energy. Therefore, one protonated state, $\mathrm{NI}^{\mathrm{H}+}$, should be the proper native intermediate state. For the RO state, two protonation states with $\mu^{3}$-oxo or $\mu^{2}-\mathrm{OH}$ were examined. The former state $\left(\mathrm{RO}_{0}\right)$, in which T3Cus and T2Cu are coordinated by $\mu^{3}$-oxo and water, respectively, is more stable than the latter $\left(\mathrm{RO}_{1}\right)$. In the $\mathrm{RO}_{0}$, all the four $\mathrm{Cu}$ atoms are $\mathrm{Cu}(\mathrm{II})$, and their related molecular orbitals in the $\beta$ LUMOs are clearly depicted in Figure 6 . After the four-electron reduction, all the $\mathrm{Cu}$ centers in the $\mathrm{FR}_{\mathrm{W}}$ and $\mathrm{FR}$ states become $\mathrm{Cu}(\mathrm{I})$. In Figure 7, the summary of the catalytic intermediates of BOD based on the present QM/MM calculations is depicted. Compared to the catalytic cycle in Figure 1, one additional protonation step seems to have appeared during the PI to NI transition. However, in Figure 1 , one deprotonation from the water coordinating to $\mathrm{T} 2 \mathrm{Cu}$ and one protonation to the $\mu^{2}$-oxo are necessary. These processes are not explicitly shown for clarity. Therefore, the catalytic cycle of 
Figure 7 indicates that the deprotonation of the T2Cu-water is not necessary and that it corresponds to a simpler reaction mechanism.
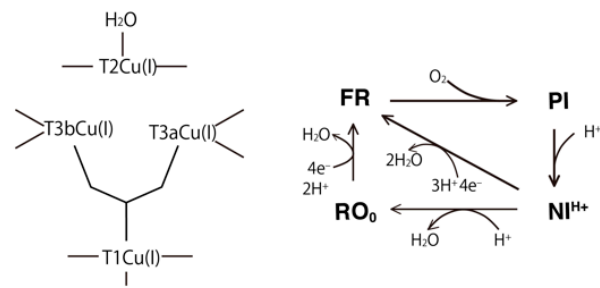

FR
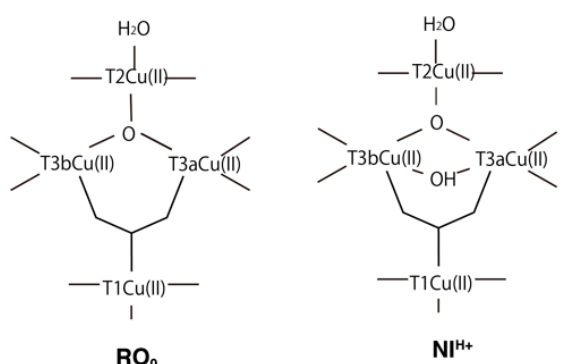

Figure 7. Schematic illustration of the catalytic cycle of BOD based on the present QM/MM calculations.

One remaining and undetermined issue for the catalytic cycle is that FR may be replaced by $\mathrm{FR}_{\mathrm{W}}$ since all the $\mathrm{X}$-ray structures in the fully reduced states are close to $\mathrm{FR}_{\mathrm{W}}$. Because the structural differences between FR and $\mathrm{FR}_{W}$ are very small, it is not easy to differentiate them except for the direct observation of the $\mu^{2}-\mathrm{O}$ electron density by $\mathrm{X}$-ray diffraction.

During the reduction, the $\mathrm{Cu}$ triangle area of the TNC increases with the loss of the $\mu^{3}$-oxo. We introduced a new index 1 to characterize the structural change. On the other hand, for $\mathrm{T} 1 \mathrm{Cu}$, very limited structural changes were calculated around $\mathrm{T} 1 \mathrm{Cu}$, which relates to the highly delocalized spin-orbital over the p orbital on the $\mathrm{S}$ atom of Cys457.

The electronic structural changes for the M467Q mutation were related to the molecular orbitals, and we showed that the energy of $\mathrm{d}$ orbital for the $\mathrm{T} 1 \mathrm{Cu}$ was raised by $\sim 1.0 \mathrm{eV}$ in $\mathrm{RO}_{0}$. Since the $\mathrm{d}$ orbitals for TNC increased by $\sim 0.4 \mathrm{eV}$, the relative increase in the orbital level of T1Cu was estimated to be $\sim 0.6 \mathrm{eV}$. Increases in the $\mathrm{Cu}$ molecular orbital levels were observed for the FR states. As the orbital level of the $\mathrm{T} 1 \mathrm{Cu}$ in $\mathrm{FR}_{\mathrm{W}}$ lies only slightly above the TNC orbitals, the redox potential of T1Cu in WT BOD is maximized as the $\mathrm{T} 1 \mathrm{Cu}$ can reduce the TNC.

Supplementary Materials: The following are available online. Figure S1: Schematic representation of the QM region, Table S1: $\beta$ molecular orbital energies in WT and M467Q BODs, Table S2: Key atomic distances, bond angles around T1Cu and TNC, Table S3: Calculated Löwdin atomic spin densities, and all the XYZ atomic coordinates in the QM regions for the WT and M467Q BODs calculated by the QM/MM method.

Author Contributions: Conceptualization, all authors; Methodology, M.S., Y.S.; Software, T.T., M.S.; Validation, all authors; Formal analysis, T.T., M.S.; investigation, T.T., M.S., Y.S.; resources, M.S., Y.S.; data curation, T.T., M.S.; writing—original draft preparation, T.T., M.S.; writing—review and editing, all authors; visualization, T.T.; supervision, Y.H., K.K., T.S., F.M.; Project Administration, N.S., Y.H., Y.S.; Funding Acquisition, M.S., V.S.

Funding: This research was funded by JSPS KAKENHI Grant Number JP16KT0055 to M.S. and project VEGA 2/0035/16 to V.S. Numerical calculations were carried out under support from (1) the "Multidisciplinary Cooperative Research Program" at the Center for Computational Sciences (CCS) in University of Tsukuba, (2) Research Center for Computational Science, Okazaki, Japan, (3) HPCI systems (Project ID: hp180163 and hp180154).

Conflicts of Interest: The authors declare no conflict of interest. 


\section{References}

1. Permyakov, E.A. Metalloproteomics; John Wiley \& Sons. Inc.: Hoboken, NJ, USA, 2009; pp. 339-388, ISBN 978-0-470-39248-5.

2. Mizutani, K.; Toyoda, M.; Sagara, K.; Takahashi, N.; Sato, A.; Kamitaka, Y.; Tsujimura, S.; Nakanishi, Y.; Sugiura, T.; Yamguchi, S.; et al. X-ray analysis of bilirubin oxidase from Myrothecium verrucaria at $2.3 \AA$ resolution using a twinned crystal. Acta Crystallogr. Sect. F Struct. Biol. Cryst. Commun. 2010, 66, 765-770. [CrossRef] [PubMed]

3. Cracknell, J.A.; McNamara, T.P.; Lowe, E.D.; Blanford, C.F. Bilirubin oxidase from Myrothecium verrucaria: $\mathrm{X}$-ray determination of the complete crystal structure and a rational surface modification for enhanced electrocatalytic $\mathrm{O}_{2}$ reduction. Dalton. Trans. 2011, 40, 6668-6675. [CrossRef] [PubMed]

4. Sakai, H.; Nakagawa, T.; Tokita, Y.; Hatazawa, T.; Ikeda, T.; Tsujimura, S.; Kano, K. A high-power glucose/oxygen biofuel cell operating under quiescent conditions. Energy Environ. Sci. 2009, 2, 133-138. [CrossRef]

5. Mano, N.; de Poulpiquet, A. $\mathrm{O}_{2}$ Reduction in Enzymatic Biofuel Cells. Chem. Rev. 2018, 118, $2392-2468$. [CrossRef] [PubMed]

6. Solomon, E.I.; Augustine, A.J.; Yoon, J. $\mathrm{O}_{2}$ Reduction to $\mathrm{H} 2 \mathrm{O}$ by the multicopper oxidases. Dalton Trans. 2008, 3921-3932. [CrossRef] [PubMed]

7. Solomon, E.I.; Sundaram, U.M.; Machonkin, T.E. Multicopper Oxidases and Oxygenases. Chem. Rev. 1996, 96, 2563-2605. [CrossRef] [PubMed]

8. Kataoka, K.; Sugiyama, R.; Hirota, S.; Inoue, M.; Urata, K.; Minagawa, Y.; Seo, D.; Sakurai, T. Four-electron Reduction of Dioxygen by a Multicopper Oxidase, CueO, and Roles of Asp ${ }^{112}$ and $\mathrm{Glu}^{506}$ Located Adjacent to the Trinuclear. Copp. Cent. J. Biol. Chem. 2009, 284, 14405-14413. [PubMed]

9. Tasca, F.; Farias, D.; Castro, C.; Acuna-Rougier, C.; Antiochia, R. Bilirubin Oxidase from Myrothecium verrucaria Physically Absorbed on Graphite Electrodes. Insights into the Alternative Resting Form and the Sources of Activity Loss. PLoS ONE 2015, 10, e0132181. [CrossRef]

10. Akter, M.; Tokiwa, T.; Shoji, M.; Nishikawa, K.; Shigeta, Y.; Sakurai, T.; Higuchi, Y.; Kataoka, K.; Shibata, N. Redox Potential-Dependent Formation of an Unusual His-Trp Bond in Bilirubin Oxidase. Chem. Eur. J. 2018. [CrossRef]

11. Shimizu, A.; Sasaki, T.; Kwon, J.H.; Odaka, A.; Satoh, T.; Sakurai, N.; Sakurai, T.; Yamaguchi, S.; Samejima, T. Site-Directed Mutagenesis of a Possible Type 1 Copper Ligand of Bilirubin Oxidase; a Met467Gln Mutant Shows Stellacyanin-Like Properties. J. Biochem. 1999, 125, 662-668. [CrossRef]

12. Kataoka, K.; Kitagawa, R.; Inoue, M.; Naruse, D.; Sakurai, T.; Huang, H. Point Mutations at the Type I Cu Ligands, Cys457 and Met467, and at the Putative Proton Donor, Asp105, in Myrothecium verrucaria Bilirubin Oxidase and Reactions with Dioxygen. Biochemistry 2005, 44, 7004-7012. [CrossRef] [PubMed]

13. Shoji, M.; Isobe, H.; Yamanaka, S.; Umena, Y.; Kawakami, K.; Kamiya, N.; Shen, J.-R.; Yamaguchi, K. Large-Scale QM/MM Calculations of Hydrogen Bonding Networks for Proton Transfer and Water Inlet Channels for Water Oxidation-Theoretical System Models of the Oxygen-Evolving Complex of Photosystem II. Adv. Quantum. Chem. 2014, 7, 325-413.

14. Shoji, M.; Isobe, H.; Nakajima, T.; Yamaguchi, K. Full geometry optimizations of the $\mathrm{CaMn}_{4} \mathrm{O}_{4}$ model cluster for the oxygen evolving complex of photosystem II. Chem. Phys. Lett. 2015, 640, 23-30. [CrossRef]

15. Shoji, M.; Isobe, H.; Shen, J.-R.; Yamaguchi, K. Geometric and electronic structures of the synthetic $\mathrm{Mn}_{4} \mathrm{CaO}_{4}$ model compound mimicking the photosynthetic oxygen-evolving complex. Phys. Chem. Chem. Phys. 2016, 18, 11330-11340. [CrossRef] [PubMed]

16. Shoji, M.; Isobe, H.; Shigeta, Y.; Nakajima, T.; Yamaguchi, K. Concerted Mechanism of Water Insertion and $\mathrm{O}_{2}$ Release during the $\mathrm{S}_{4}$ to $\mathrm{S}_{0}$ Transition of the Oxygen-Evolving Complex in Photosystem II. J. Phys. Chem. $B$ 2018, 122, 6491-6502. [CrossRef] [PubMed]

17. Shoji, M.; Yoshioka, Y.; Yamaguchi, K. An efficient initial guess formation of broken-symmetry solutions by using localized natural orbitals. Chem. Phys. Lett. 2014, 608, 50-54. [CrossRef]

18. Komori, H.; Sugiyama, R.; Kataoka, K.; Higuchi, Y.; Sakurai, T. An O-Centered Structure of the Trinuclear Copper Center in the Cys500Ser/Glu506Gln Mutant of CueO and Structural Changes in Low to High X-Ray Dose Conditions. Angew. Chem. Int. Ed. 2012, 51, 1861-1864. [CrossRef] 
19. Valiev, M.; Bylaska, E.J.; Govind, N.; Kowalski, K.; Straatsma, T.P.; van Dam, H.J.J.; Wang, D.; Nieplocha, J.; Apra, E.; Windus, T.L.; et al. NWChem: A comprehensive and scalable open-source solution for large scale molecular simulations. Comput. Phys. Commun. 2010, 181, 1477-1489. [CrossRef]

20. Becke, A.D. Density-functional thermochemistry. III. The role of exact exchange. J. Chem. Phys. 1993, 98, 5648-5652. [CrossRef]

21. Grimme, S.; Ehrlich, S.; Goerigk, L. Effect of the damping function in dispersion corrected density functional theory. J. Comput. Chem. 2011, 32, 1456-1465. [CrossRef]

22. Wang, J.; Cieplak, P.; Kollman, P.A. How well does a restrained electrostatic potential (RESP) model perform in calculating conformational energies of organic and biological molecules? J. Comput. Chem. 2000, 21, 1049-1074. [CrossRef]

23. Hay, P.J.; Wadt, W.R. Ab initio effective core potentials for molecular calculations. Potentials for $\mathrm{K}$ to $\mathrm{Au}$ including the outermost core orbitals. J. Chem. Phys. 1985, 82, 299-310. [CrossRef]

24. Hehre, W.J.; Ditchfield, R.; Pople, J.A. Self-Consistent Molecular Orbital Methods. XII. Further Extensions of Gaussian-Type Basis Sets for Use in Molecular Orbital Studies of Organic Molecules. J. Chem. Phys. 1972, 56, 2257-2261. [CrossRef]

25. Hariharan, P.C.; Pople, J.A. The influence of polarization functions on molecular orbital hydrogenation energies. Theor. Chim. Acta. 1973, 28, 213-222. [CrossRef]

26. Francl, M.M.; Pietro, W.J.; Hehre, W.J.; Binkley, J.S.; Gordon, M.S.; DeFrees, D.J.; Pople, J.A. Self-consistent molecular orbital methods. XXIII. A polarization-type basis set for second-row elements. J. Chem. Phys. 1982, 77, 3654-3665. [CrossRef]

27. Sondergaard, C.R.; Olsson, M.H.M.; Rostkowski, M.; Jensen, J.H. Improved Treatment of Ligands and Coupling Effects in Empirical Calculation and Rationalization of $\mathrm{p} K_{\mathrm{a}}$ Values. J. Chem. Theory Comput. 2011, 7, 2284-2295. [CrossRef] [PubMed]

28. Olsson, M.H.M.; Sondergaard, C.R.; Rostkowski, M.; Jensen, J.H. PROPKA3: Consistent Treatment of Internal and Surface Residues in Empirical $\mathrm{p} K_{\mathrm{a}}$ Predictions. J. Chem. Theory Comput. 2011, 7, 525-537. [CrossRef] [PubMed]

29. DeLano, W.L. The PyMOL Molecular Graphics System, version 1.8; DeLano Scientific LLC: Palo Alto, CA, USA, 2015.

30. Tokiwa, T.; Nakano, S.; Yamamoto, Y.; Ishikawa, T.; Ito, S.; Sladek, V.; Fukuzawa, K.; Mochizuki, Y.; Tokiwa, H.; Misaizu, F.; et al. Development of an Analysis Toolkit, AnalysisFMO, to Visualize Interaction Energies Generated by Fragment Molecular Orbital Calculations. J. Chem. Inf. Model. 2018. [CrossRef] [PubMed]

31. Humphery, W.; Dalke, A.; Schulten, K. VMD: Visual Molecular Dynamics. J. Mol. Graph. 1996, 14, $27-28$. [CrossRef]

Sample Availability: Samples of the compounds are not available from the authors.

(C) 2018 by the authors. Licensee MDPI, Basel, Switzerland. This article is an open access article distributed under the terms and conditions of the Creative Commons Attribution (CC BY) license (http://creativecommons.org/licenses/by/4.0/). 